supported by the influence of the scientific men of the country, such a bill could, we feel certain, be passed through Congress, liberating us from this tax, which falls heavier on men the poorer they are and the more faithfully they try to do their duty.

Some of our most esteemed literary idols have lately astonished us by signing a statement which seems to imply, that, in their opinion, American literature needs coddling to keep it alive. They must decide in their own line of work. We are certainly not less proud of, or less desirous to cherish, American science than they are American letters, and, we are bold enough to think, with at least as much reason. We are sure that we give expression to the conviction of all American scientific men when we say that we believe in no isolated American science. The accurate study of nature is the common duty of all civilized peoples: what each does helps all the rest.

In this connection, we are rejoiced to find that most American artists have taken a position in regard to art agreeing with ours in regard to science. The attitude lately taken by certain prominent authors is but one sign, among several, of a certain tendency in Literature to fall from its former lofty ideals; and, losing the characteristics of a profession, to become simply a trade, followed for the sole sake of the money to be made at it. If this does happen, then Art and Science will have to take the place once held by Letters, and strive to keep alive the belief that there are more worthy aims in life than getting the largest possible number of dollars for one's work, whatever it be. We do not, however, now ask our literary friends to expose themselves to a promiscuous, and, as they appear to think, debasing competition: we only ask to be allowed, duty free, a limited number of purely technical journals; and we shall still read with delight the Autocrat and the Professor, although sorely pained that our own familiar friend, in whom we trusted, has done what lay in his power to make it difficult for us to learn our anatomy.

\section{THE MICROSCOPIC EVIDENCE OF A LOST CONTINENT.}

Much interest has been attached to St. Paul's rocks, situated in the mid-Atlantic nearly under the equator; since they were stated by Darwin ${ }^{1}$ to be unlike any rock he had ever met, and that they were not volcanic. Darwin's words have caused these rocks to be looked upon as forming a portion of the lost Atlantis; those holding that view overlooking the fact that Darwin simply meant that they were not rocks of volcanic origin such as those he had any acquaintance with. That they were not eruptive or volcanic of earlier date than the other islands in the Atlantic, he was not in a position to assert, and evidently did not intend to do so. Being of different material from the other Atlantic islands, they might even be of comparatively modern origin, and still not show especial traces of their eruptive character. Situated as these islands are, no relation of the rocks of which they are composed to the adjacent rocks can be ascertained: hence the only resort is to study the structure and composition of the rock-mass itself, and to ascertain what evidence it may afford.

When these rocks were examined in situ by the members of the Challenger expedition, they were thought by $\mathrm{Mr}$. Buchanan to be referable to the serpentine group, but by Prof. Wyville Thomson to have been formed by the ' ejecta of sea-fowl.' 2

In this state of affairs, the material collected was wisely placed by Mr. John Murray, who had charge of the Challenger material, in the hands of a competent lithologist, Rev. A. Renard, S.J., curator of the royal museum of natural history at Brussels.

When studied microscopically these rocks were found to be composed of olivine, enstatite, actinolite, chromite, or picotite, and a pyroxene mineral. When M. Renard first examined these rocks, he thought that he discovered in them certain structures which he regarded as fluidal. ${ }^{3} \quad \mathrm{He}$ therefore held that these rocks were of eruptive origin ; but in some publications recently issued he has modified his views, and is inclined to regard the structures seen as schistose and not fluidal. ${ }^{4}$

M. Renard then endeavors to show that these may be metamorphic sedimentary rocks

\footnotetext{
1 Volcanic islands, 1851, pp. 31-33, 125.

2 Voyage of the Challenger, ii. 100-108.

3 Neues Jahrb min., 1879, 389-394.

4 Description lithologique des récifs de St. Paul (Ann. soc. belge micr., 1882, 53 pp.); Report on the petrology of the rocks of St. Paul (Scient. results voyage Challenger, 1873-76, Narrative, 1882 , ii. app. $B, 29$ pp., 1 plate).
} 
and therefore, according to him, true schists; hence he would argue they are the remains of an extensive land area - an Atlantis - of which, owing to denudation, only these few remains are left. His arguments are based on the apparent microscopic schistose structure of the St. Paul's rock, and on the fact that certain olivine rocks have been found associated.with crystalline schists.

In examining the first evidence, the writer may state, that he has in his possession two specimens of these rocks, sent him by Mr. John Murray ; and therefore the evidence that their sections afford will be given. The sections of one - the least altered - are composed of olivine, enstatite, diallage, picotite or chromite, magnetite, pyrite, actinolite, and serpentine.

While M. Renard remarks that all the minerals have their principal axis parallel with the supposed schistose or fluidal structure, they are found by me to stand in every direction regarding that structure, - even at right angles to one another. Indeed, no structure has been seen by me that I can regard as truly schistose or fluidal.

A structure does exist somewhat resembling a schistose one, which appears to be the result of secondary alteration of the rock-mass. M. Renard states that the rock is fresh and unaltered in certain of the specimens, and one of mine answers to his description of his supposed unaltered rock. He further states, that the structure of this rock is peculiar, and unlike that of other olivine rocks. My sections lead me to a somewhat different conclusion. In them, portions were found that I regard as the original, unaltered rock. 'These showed the same structure and characters that other unaltered olivine rocks show, and do not appear to be of any abnormal type.

The main portion of the rock which M. Renard regarded as groundmass, and held to be unchanged, is, in my opinion, greatly altered, and contains only remnants of the original minerals of the rock. He regards this groundmass as composed entirely of olivine grains, but of this I have grave doubts. 'The microscopic characters of this groundmass do not appear to me to be those of ordinary olivine, but rather those of minerals of secondary origin. That this groundmass is of secondary origin, for the most part, is shown by its occurrence along the fissures in the unaltered olivine; by its relations to the minerals that it surrounds, - which relations are the same as those existing between the original minerals and their alteration products in other rocks; and by the so-called schistose structure. I do not design to call in question the work of M. Renard, who is a thoroughly competent observer, and whose sections have not been seen, but rather to show that the characters in my sections do not, in my judgment, bear out the conclusion derived by him from his. Questions of this kind are largely dependent upon the methods of work and the kind of study to which the observer has devoted himself. M. Renard has given much time to the study of crystalline schists and the older eruptive rocks; while the present writer has, for a number of years, devoted much of his time to the study of unaltered rocks, and to the tracing of their various types through to the extreme phases of alteration, studying both modern and ancient forms, with especial reference to their origin and development. It is therefore natural that we should both look at the St. Paul's rocks from a somewhat different stand-point.

But to continue. It is contrary to the laws of physics and chemistry, that a mineral in the process of alteration should produce itself again. Alteration is rather a passage from an unstable to a more stable compound in the conditions to which the rock is then exposed: hence the resulting mineral in this case must belong either to another variety of olivine, or to a distinct mineral species. This would hold good if more than one mineral should be formed.

The actinolite, picotite or chromite, magnetite, pyrite, and serpentine, are regarded by me as secondary products in this case, and not original minerals.

In the places showing the unaltered condition of the rock, the granular structure is the same as that believed to be due to crystallization from an igneous magma, and not owing to detrital action.

The specimens sent me show that they are surface and weathered specimens, to which cause is probably due much of the difficulty met in their study. It is to be hoped, that, should St. Paul rocks be visited again, great pains will be taken to procure specimens as far in the solid rock as possible.

Microscopically, then, the writer holds that these rocks afford evidence in their structure and composition favoring the view that they are eruptive, while in his sections he can find nothing supporting the theory of M. Renard.

It now remains to look at the question of the association of olivine rocks with schists as proving that they are both of a common origin.

This line of argument the writer had occa- 
sion to meet in reference to rocks of a different composition a few years ago. ${ }^{1}$ M. Renard's line of argument would prove that a dike in conglomerate had the same origin as the conglomerate itself, - would prove, that, when sandstones and lava-flows are interbedded, both have a common origin. In any volcanic district we have mingled in inextricable confusion lava-flows, ashes, scoriae, dikes, and sedimentary rocks : are these all of common origin because they are associated? Is a lavaflow, buried by the seashore sands, of like origin with the sand? In our older rocks we have dikes cutting in every direction : are they the same as the rocks they cut?

The only proof regarding the origin of associated rocks is the relation that they bear to one another: the mere fact of association in itself is no proof.

In another respect M. Renard's argument is faulty, inasmuch as it assumes that all crystalline schists are of sedimentary origin. Eruptive are, as a rule, more subject to alteration than sedimentary rocks ; therefore, in proportion to their abundance, they are more commonly found as metamorphic rocks than the others. One of the common metamorphosed characters of eruptive rocks is a schistose structure, and the mere fact that a rock shows such a structure affords no proof of its origin. The writer has seen a well-marked schist cutting in a dike directly across the stratification of a conglomerate, - it was, of course, a metamorphosed basic, eruptive rock, - and he has seen numerous other examples of a similar character.

The best evidence regarding the origin of the olivine rocks is in behalf of their eruptive characters, as M. Renard points out: on the other side, positive evidence seems to be wanting, it being rather a matter of personal opinion than facts. In such cases as those examined by Professor Bonney, and the one studied by the present writer on Lake Superior, the facts and evidence in behalf of their eruptive origin are clear and explicit. So far, then, as the mineralogical constitution of the St. Paul's rocks go, it points rather towards an eruptive than a sedimentary origin for them.

Indeed, did it not, it is difficult to see how any denudation could take place so far down in the sea, as is here required, when, as M. Renard admits, there is no evidence that any sinking has occurred. ${ }^{2}$

The writer would therefore hold that the St. Paul's rocks offer no evidence in favor of

\footnotetext{
1 Proc. Bost. soc. nat. hist., 1880, xx. 470-479.

2 See also Prof. A. Geikie, Nature, 1882, xxvii. 25, 26.
}

their being the remains of a lost Atlantis; but rather that they are of eruptive origin, like the other Atlantic islands, although probably of earlier date than the prevailing rocks upon the latter.

M. E. Wadsworth.

\section{THE PASCAL HEXAGRAM.}

The Royal academy of Belgium in 1879, and again in 1881, offered its prize for a solution of the following question: "To extend as much as possible the theories of the points and lines of Steiner, Kirkman, Cayley, Salmon, Hesse, Bauer, to the properties which are, for higher plane curves and for surfaces and curves in space, the analogues of the theorems of Pascal and Brianchon (see, for these last, the writings of MM. Cremona, P. Serret, and Folie).", The only contestant for the prize in 1881 was Professor Veronese of the university of Padua, whose work on the subject of the original theorems was already well known. To the paper submitted by him, the Belgian academy, advised by its committee, consisting of MM. Folie, Catalan, and de Tilly, declined to award the prize; and the paper has, in consequence, been published in full in the Annali di matematica (xi., Dec., 1882, 143 p.) with the report of M. Folie, and a commentary thereon by Veronese. It is a controversy of unusual liveliness for a mathematical one. Before entering upon its merits, we shall give a summary of the memoir of Professor Veronese.

The extensions of the properties of the Pascal hexagram hitherto proposed have been special, and not general, and hence are incapable of being carried farther. When, for instance, the six perfectly arbitrary points on the conic are replaced by six generatrices of the hyperboloid, three must be taken from one system, and three from the other ; and one gets, with this restriction, only a single pair of lines, corresponding to one conjugate pair of the twenty Steiner points. Cremona's extension to a cubic in space, on the other hand, can be obtained by simple projection from the hexagram in a plane conic. To develop these special, uninteresting, easy results would not be, according to Veronese, to answer the proposed question; so, leaving them one side, he proceeds to the application of a different method, - the theory of substitutions. His method is, in brief, to represent the six points on a conic by six values of a parameter, whose permutations give, from any figure whatever which they represent, seven hundred and twenty figures of the same kind, or a divisor of 720 . If, for 